\section{Symptomatic esophageal ulceration caused by a Bravo wireless pH probe and subsequent endo- scopic removal of the probe using a retrieval net}

A 56-year-old woman with a history of osteoporosis and hyperlipidemia presented for evaluation of gastroesophageal reflux disease. She had undergone a normal esophagogastroduodenoscopy examination within the previous 12 months and had had an incomplete response to treatment with proton-pump inhibitors. Because of her symptoms, she was referred for wireless $\mathrm{pH}$ monitoring using the Bravo system (Medtronic, Minneapolis, Minnesota, USA). The patient underwent an uneventful placement of the Bravo probe.

She presented 48 hours later with severe anterior thoracic pain and esophagogastroduodenoscopy was performed. The Bravo probe was identified in the distal esophagus (Figure $\mathbf{1}$ ), and a small, cleanbased ulcer was observed at the attachment site. It was not possible to dislodge the $\mathrm{pH}$ probe by applying gentle pressure from the tip of the endoscope, and a Roth Net (US Endoscopy, Mentor, Ohio, USA) was then used to grasp the probe firmly and detach it from the esophagus (Figure $\mathbf{2}$ ). The patient's symptoms improved after removal of the $\mathrm{pH}$ probe.

Chest pain is a rare, but recognized side effect of $\mathrm{pH}$ monitoring using the Bravo probe. At least four patients have experienced chest pain severe enough to warrant endoscopic removal of the probe [1, 2]: these probes were removed by applying gentle pressure from the tip of the endoscope or by grasping the probe with biopsy forceps. This is the first description of probe removal using a retrieval net. In addition, the esophageal ulceration noted in this case was not described in the previous cases. This case highlights a possible complication of wireless $\mathrm{pH}$ testing and descibes endoscopic management of this rare event.

Endoscopy_UCTN_Code_CPL_1AH_2AJ

Endoscopy_UCTN_Code_TTT_1AO_2AM

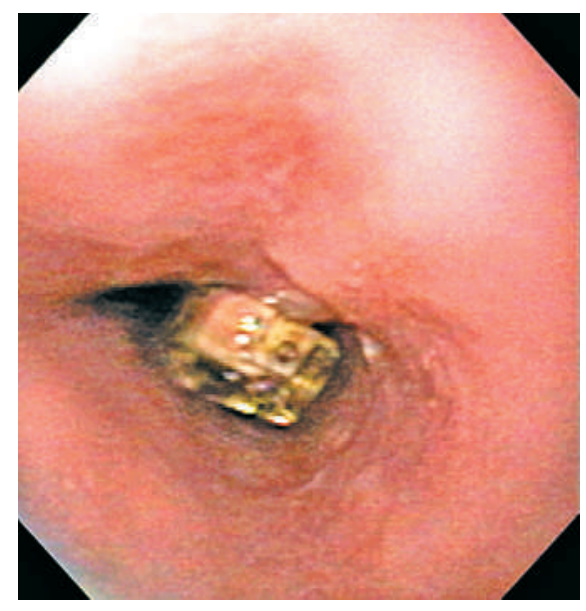

Figure 1 The Bravo probe was identified in the distal esophagus.

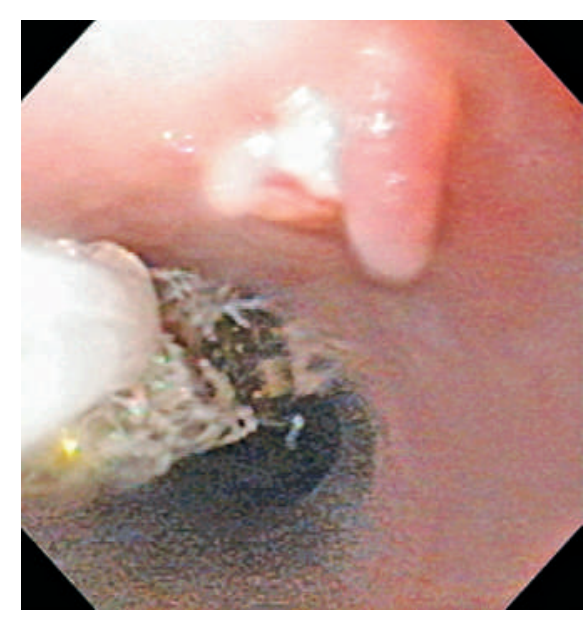

Figure 2 A retrieval net (Roth Net; US Endoscopy, Mentor, Ohio, USA) was used to grasp the probe firmly and detach it from the esophagus.

\section{D. Wells, R. I. Heigh, G. E. Burdick,} M. M. Moirano, D. E. Fleischer

Division of Gastroenterology and Hepatology, Mayo Clinic, Scottsdale, Arizona, USA.
References

${ }^{1}$ Pandolfino JE, Kahrilas PJ. Prolonged $\mathrm{pH}$ monitoring: Bravo capsule. Gastrointest Endosc Clin N Am 2005; 15: 307-318

2 Triester SL, Leighton JA, Budavari AI et al. Severe chest pain from an indwelling Bravo $\mathrm{pH}$ probe. Gastrointest Endosc 2005; 61: $317-$ 319

\section{Corresponding Author}

\section{R. I. Heigh, M.D.}

Division of Gastroenterology and

Hepatology

Mayo Clinic

13400 East Shea Boulevard

Scottsdale

Arizona 85259

USA

Fax: $\quad+1-480-301-8673$

E-mail: heigh.russell@mayo.edu 